\title{
Skilled delivery care service utilization in Ethiopia: analysis of rural-urban differentials based on national demographic and health \\ survey (DHS) data
}

Melaku Fekadu ${ }^{1}$ Nigatu Regassa ${ }^{2}$

1. Wollo University, College of Natural Sciences,Department of Statistics, Dessie, +2519110861 39. Email: Fekadumelaku@yahoo.com

2. Hawassa University, Institute of Environment, Gender and Development, E-mail: negyon@yahoo.com: P.O.Box 679, Hawassa, SNNPR, Ethiopia; Phone 251-046-2206975

\section{Abstract}

Background: Despite the slight progress made on Antenatal Care (ANC) utilization, skilled delivery care service utilization in Ethiopia is still far-below any acceptable standards. Only $10 \%$ of women receive assistance from skilled birth attendant either at home or at health institutions, and as a result the country is recording a high maternal mortality ratio (MMR) of 676 per 100,000 live births (EDHS, 2011). Hence, this study aimed at identifying the rural-urban differentials in the predictors of skilled delivery care service utilization in Ethiopia.

Methods: The study used the recent Ethiopian Demographic and Health Survey (EDHS 2011) data. Women who had at least one birth in the five years preceding the survey were included in this study. The data were analyzed using univariate (percentage), bivariate (chi-square) and mulvariate (Bayesin logistic regression).

Results: The results showed that of the total 6,641 women, only $15.6 \%$ received skilled delivery care services either at home Results: The resuts skilled delivery $4.5 \%$ wors ether at home or at health institution. Rural women were at greater disadvantage to receive the service. Only $4.5 \%$ women in rural areas received assistance from skilled birth attendants (SBAs) compared to $64.1 \%$ of their urban counter parts. Through Bayesian logistic regression analysis, place of residence, ANC utilization, women's education, age and birth order were identified as key predictors of service utilization.

Conclusion: The findings highlight the need for coordinated effort from government and stakeholders to improve women's education, as well as strengthen community participation. Furthermore, the study recommended the need to scale up the quality of ANC and family planning services backed by improved and equitable access, availability and quality of skilled delivery care services.

Key words: antenatal care, differentials, skill birth attendance, delivery service

DOI: http://dx.doi.org/10.4314/ahs.v14i4.29

\section{Background}

Pregnancy is often a defining phase in a woman's life, and it can be a joyful and fulfilling period for the mother both as an individual and as a member of society.
However, it can also be a period of misery and suffering However, it can also be a period of misery and suffering when it is unwanted, or when complications or adverse
circumstances compromise the pregnancy, cause il

\section{Correspondence author:}

Nigatu Regassa

Institute of Environment, Gender and Development Hawassa University

P. O. Box 679

Hawassa, SNNPR, Ethiopia

Phone 251-46-2203801

Email: negyon@yahoo.com health or even maternal death. World health organization (WHO), in its 2005 world health report emphasizes that pregnancy may be natural, but that does not mean it is problem-free ${ }^{30}$

Worldwide an estimated 287,000 maternal deaths occurred in $2010^{29}$, though between $88-98 \%$ of these deaths are preventable. Nearly all (99\%) of these deaths occur in developing regions. For instance, developing regions like Sub-Saharan Africa alone account for more than one third of the global maternal deaths ${ }^{32}$. In this region, the MMR is 640 per 100,000 live births, which is in stark contrast to the situation in developed region where the figure is only 14 deaths per 100,000 live births 32. The lifetime risk of maternal death in Sub-Saharan Africa is 1 in 16 while in affluent countries the figure is 1 in 2800 .

Three quarters of all maternal deaths are known to be due to direct obstetric causes such as hemorrhage, abortion, sepsis, and ruptured uterus and hypertensive diseases of pregnancy ${ }^{30}$. Possible explanations for these deaths in developing regions are the inadequate access to modern health care services and the poor use of these services?.

Skilled attendance during pregnancy and early post natal checkup are the most appropriate interventions in preventing maternal death and will help in attaining the Millennium Development Goal (MDG 5), which aims at improving maternal health, and has specific targets of reducing the maternal mortality ratio by three quarters between the years 1990 and 2015, and to have more than $85 \%$ of deliveries assisted by skilled attendants globally by 2010 and $90 \%$ by 2015 (Starrs, 2006 and UN, 2011)

In developed countries, WHO estimates skilled attendance to have reached $99.5 \% \%^{31}$. In developing regions, the proportion of deliveries attended by skilled health personnel rose from $55 \%$ in 1990 to $65 \%$ in 2010

${ }^{29}$. The regions with the lowest proportions of skilled health attendants of birth are Sub-Saharan Africa (45\%) and Southern Asia (49\%), which also had the highest number of maternal death ${ }^{29}$. In every region, the presence of skilled birth attendants is lower in rural than in urban $\operatorname{areas}^{29}$

The health care system in Ethiopia is among the least developed in Sub-Saharan Africa, and is not, at present, able to effectively cope with the significant health problems the country is facing. The government of Ethiopia issued its health policy in 1993, which emphasizes the importance of achieving access to basic primary health care services for all segments of the population. The HSDP has also given a great attention to maternal health by recognizing the importance of the use of assistance from skilled personnel during delivery. The weak organization and performance of health services due to lack of trained personnel, lack of basic equipment and poor referral linkage can be taken as possible reasons for the low utilization of maternal health services. This creates a challenge to improve maternal health ${ }^{13}$.

In Ethiopia, an estimated 2.9 million women give birth every year. Of these, approximately over 25,000 women and girls die each year and more than 500,000 suffer from serious injuries and permanent damage to their ealth, such as obstetric fistulas. It is estimated that (100,000 women suffer with untreated fistulas across the country and another 9,000 women develop fistula every year which is mainly caused by obstructed labor and lack of maternal health care ${ }^{12}$.

Consequently in Ethiopia, the observed change in maternal mortality is very low and there is a need to accelerate the decline in mortality in order to achieve the MDG of reducing maternal mortality by two third. The maternal mortality rate was estimated to be $676 / 100,000$ according to the 2011 EDHS. The annual percentage change is only -4.2 , which puts the country off-track but still in the category of "making progress" towards the target set under MDG-5 $5^{32}$.

Furthermore, the challenges of maternal mortality and morbidity in the country are aggravated by the underutilization of skilled delivery care services. According to Ethiopian demographic health survey (EDHS), 2011 report, only ten \% of births in Ethiopia are delivered with the assistance of skilled birth attendants. Nine women in every ten deliver at home, i.e., only ten $\%$ of births were assisted by skilled service providers, and $57 \%$ of births were assisted by relatives, or some other persons. Twenty- eight $\%$ of births were assisted by traditional birth attendants, while $4 \%$ of births were unattended.

The very few case studies conducted indicated that number of individual, household and institutional characteristics affect women's decisions of seeking delivery care, which includes education, income, accessibility, age, organization and functioning of the health care system and services, interaction between parents and health workers, waiting time and clinical practice ${ }^{1}$. Mengistu and James, in their study in the Arsi Zone of central Ethiopia, found maternal age, parity, lack of time, education, marital status, and women's economic status to be significant predictors of utilization of maternity care $^{19}$. A study in Yirgalem Town and in the surrounding Southern Nations, Nationalities, and People's Region (SNNPR) of Ethiopia showed that women's education, inadequate household income, and un wanted pregnancy were important predictors of antenatal and delivery care utilization ${ }^{35}$. A recent study conducted in Southern Ethiopia ${ }^{23}$ identified that women's age, work status, literacy status, children ever born, and exposure to media( frequency of listening to radio) were the key predictors of delivery service utilization. There could 
also be many other factors that can explain why women prefer not to utilize necessary health services during pregnancy ${ }^{26}$.

To the best knowledge of the authors, the very few studies conducted previously were either based on small sample or small segment of a population or were based on secondary data available in health facilities. Thi study therefore examined the rural urban differential in the predictors of skilled delivery care service utilization in Ethiopia based on 6641 women.

\section{Conceptual framework}

The behavioral model adopted from Anderson et al. ${ }^{4}$ provides a framework for understanding the potential influences on an individual's decision to make use of the available health services. The model suggests that

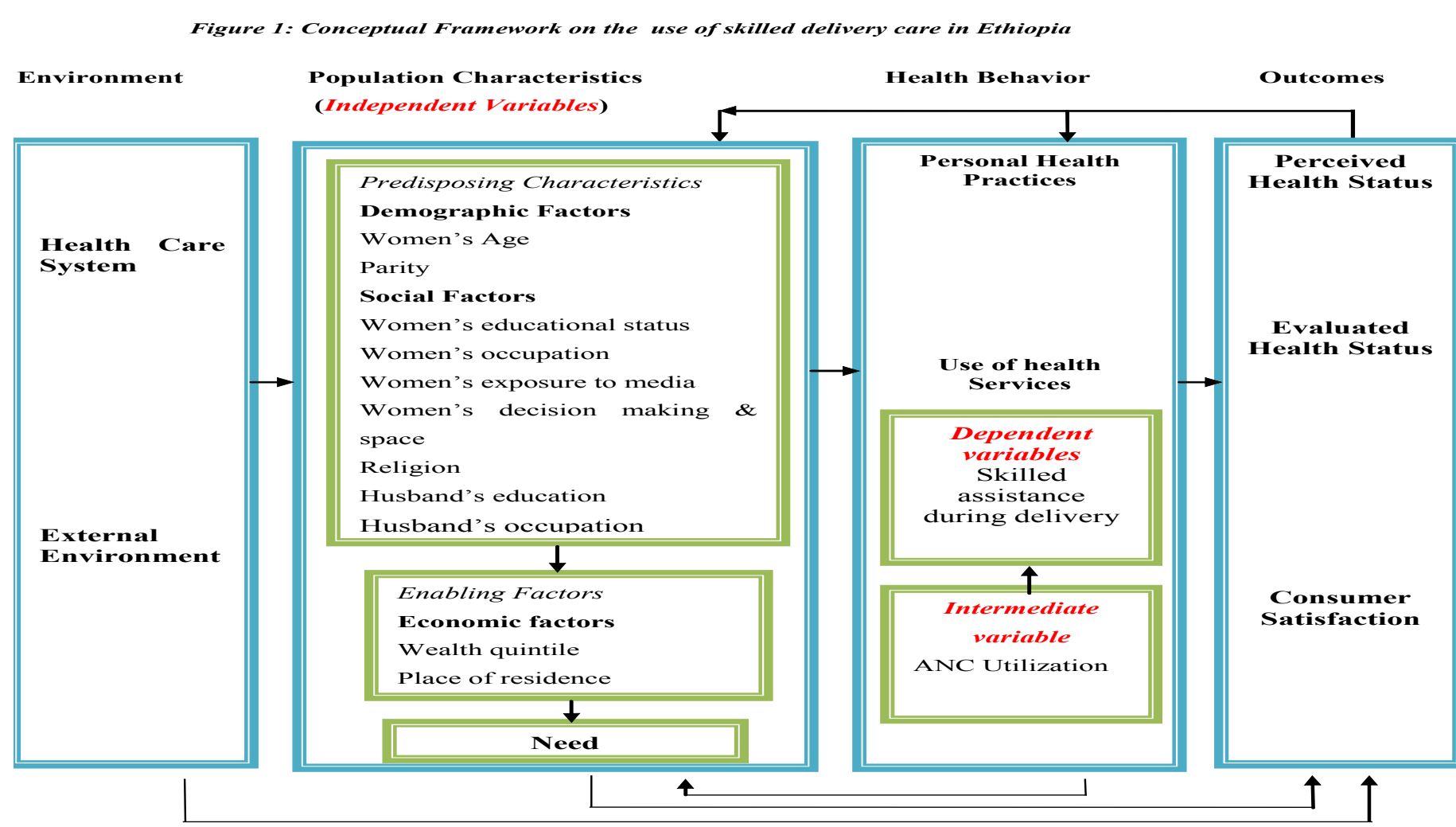

Source: Anderson, R.M (1995): Behavioral Model of Health Services Utilization

(districts) and 15,000 Kebeles. Regions are divided into next to Nigeria. The third census conducted in 2007 zones, and zones, into administrative units called revealed that the country has a total population of 74 weredas. Each wereda is further subdivided into the million. Of these, $50.5 \%$ were males and $49.5 \%$ were lowest administrative unit called kebele (Population females and a large proportion of women (24\%) were Census Commission, 2008). in the reproductive age (15-49 years).

Ethiopia is the second most populous nation in Africa Ethiopia is one of the world's poorest countries. The country's per capita income of US $\$ 370$ is substantially lower than the regional average of US\$1,257.The government aspires to reach middle income status (current threshold: US\$1,025) over the next decade. The recent economic growth brought with it positive trends in reducing poverty, in both urban and rural areas. While $38.7 \%$ of Ethiopians lived in extreme poverty in 2004 2005 , five years later this number was reduced to $29.6 \%$ which is a decrease of $9.1^{34}$.

Source of Data, Instruments of Data Collection and Sampling design

This study is conducted based on the national EDHS 2011 which was carried out un Ministry of Health $(\mathrm{MOH})$ and was implemented by the Central Statistical Agency (CSA). The survey is part of the worldwide Demographic and Health Survey (DHS) program, which is designed to provide information on population, family planning, and health. The 2011 EDHS is the third demographic and health survey conducted in Ethiopia since 2001.

The 2011 EDHS used three questionnaires: the Household Questionnaire, the Women's Questionnaire, and the Men's Questionnaire. These questionnaires were adapted from model survey instruments developed for the MEASURE DHS project to reflect the population and health issues relevant to Ethiopia. Issues were identified at a series of meetings held with various stakeholders.

The components of maternal health care covered in the survey included antenatal care, delivery and postnatal care. Women aged 15- 49 who gave birth within five years preceding the survey were asked information on utilization of skilled delivery care services. If the woman had more than one child in the five years preceding the survey, information on the use of delivery assistance was collected for the last birth.

The EDHS is basically a descriptive cross-sectiona survey which employed quantitative research methods . The sample for the 2011 EDHS was designed to provide population and health indicators at the national urban and rural) and regional levels. The sample design allowed for specific indicators to be calculated for each of Ethiopia's 11 geographic/administrative regions (the nine regional states and the two city administrations). The 2007 Population and Housing Census, conducted the CSA provided the sampling frame from which EDHS sample was drawn.

The 2011 EDHS sample was selected using a stratified, two-stage cluster design and EAs were the sampling units for the first stage. The sample included $624 \mathrm{EAs}$, 187 in urban areas and 437 in rural areas. Households comprised the second stage of sampling. A complete listing of households was carried out in each of the 624 selected EAs from September 2010 through January 2011. Sketch maps were drawn for each of the clusters, and all conventional households were listed. The isting excluded institutional living arrangements and collective quarters (e.g., army barracks, hospitals, police camps, and boarding schools).

A total of 17,817 households were selected for the sample, of which 17,018 were found to be occupied during data collection. Of these, 16,702 were successfully interviewed, yielding a household response rate of 98 $\% .17,385$ eligible women were identified for individual interview and complete interviews were conducted with 16,515 women, vielding a response rate of 95 $\%$.In this study, visitors were excluded and only women who gave birth in the past five years preceding the survey were included. As a result, the analysis of this study was carried out using 6,641 women because the sample is not self- weighted at the national level, all data in this report are weighted unless otherwise specified.

\section{Variables in the Study}

In the 2011 EDHS, the respondents (ever-married women aged 15-49) were asked questions regarding their last birth that occurred in the five years preceding the survey as to who assisted them with the delivery. From this specific question, dichotomous variables were created for this study. It was coded as 1 if the woman received assistance at delivery from SBAs including qualified Doctor, Nurse or Midwife, and 0 if otherwise.

Based on the Andersen's behavioral model of the use of health services, twelve independent variables were included in this study: nine variables from predisposing factors, two from enabling factors and one from personal health practices (ANC utilization).

\section{Method of Data Analysis}

Data cleaning and management were carried out using VTATA, Version 12. Variables were re-coded to meet the desired classification. The study employed 
univariate, Bivariate and multivariate analysis. Univari- all sample, almost half $(50 \%)$ of women were in the ate analysis was carried out to describe women's demo- age group 25-34 years old. The majority of the women graphic and socio-economic characteristics. Bivariate (56.1\%) in urban areas had one or two children. Conanalysis was used to see simple association between the versely, relatively higher proportion (39.1\%) of women dependent and explanatory variables. Further, because in rural areas gave birth to 3-5 children (Table 1).

of the complexity of relationships between the depend-

ent and independent variables, multivariate analysis in a The majority of women in the overall sample had neve form of Bayesian logistic regression was also employed. been in school $(67.9 \%)$. Notable variations in attendTo estimate the effect of the indicator variables on the ing school was observed between rural and urban outcome variable, Odds ratio (OR) and $95 \%$ confidence women. Accordingly, $75.8 \%$ of women in rural areas interval $(\mathrm{CI})$ were computed.

\section{Results}

Background Characteristics

There were 6,641 women included in this study. An for almost $30 \%$. Women in urban and rural areas who overwhelming majority of the respondents were rural belong to the poorest wealth quintile were 4.2 and 35.5 residents, consisting of $81.4 \%$ of the total respondents, \%, respectively (Table 1 ).

and the rest $18.6 \%$ were from urban areas. As indicated Urban-rural disparity with respect to women's occupain table 1, the highest proportions of women were from tion showed that almost $42 \%$ of women in urban areas Oromiya $(14.7 \%)$, while the least proportion of women engaged in skilled work compared to $19.6 \%$ of their were included from Addis Ababa (4.3\%). In the over- rural counterparts. With respect to ANC utilization, it

\begin{tabular}{|c|c|c|c|c|}
\hline \multirow{2}{*}{ Background characteristics } & & \multicolumn{2}{|c|}{ Place of Residence (\%) } & \multirow{2}{*}{ Total } \\
\hline & $\mathrm{n}$ & Urban & Rural & \\
\hline $\begin{array}{l}\text { Parity } \\
1-2\end{array}$ & 2251 & & & \\
\hline 3-5 & 2510 & 32.0 & 39.1 & 37.8 \\
\hline & 1879 & 11.9 & 32.0 & 28.3 \\
\hline \multicolumn{5}{|l|}{ Respondent's age } \\
\hline $15-24$ & 1667 & 26.0 & 24.9 & 25.1 \\
\hline $\begin{array}{l}25-34 \\
35-49\end{array}$ & 3314 & $\begin{array}{l}56.4 \\
17.6\end{array}$ & $\begin{array}{l}48.4 \\
26.7\end{array}$ & \\
\hline \multicolumn{5}{|l|}{ Women's education } \\
\hline No education & 4509 & 33.2 & 75.8 & 67.9 \\
\hline Primary education & 1727 & 39.3 & 23.0 & 26.0 \\
\hline $\begin{array}{l}\text { Secondary education } \\
\text { Husband's education }\end{array}$ & 405 & 27.5 & 1.2 & 6.1 \\
\hline \multicolumn{5}{|l|}{$\begin{array}{l}\text { Husband's education } \\
\text { No education }\end{array}$} \\
\hline Primary education & 2464 & 40.8 & 36.2 & 37.1 \\
\hline $\begin{array}{l}\text { Secondary/higher education } \\
\text { Respondent's occupation }\end{array}$ & 830 & 40.3 & 6.1 & 12.5 \\
\hline Unskilled & 5067 & 58.1 & 80.4 & 76.3 \\
\hline \multirow{2}{*}{\multicolumn{2}{|c|}{ Husband's occupation }} & 41.9 & 19.6 & \\
\hline & 4928 & 17.0 & 87.2 & \\
\hline Skilled & 1713 & 83.0 & 12.8 & 25.8 \\
\hline \multicolumn{4}{|l|}{ Religion } & 33.0 \\
\hline Protestant & 1275 & 11.8 & 20.8 & 19.2 \\
\hline Muslim & 2982 & 40.4 & 45.9 & 44.9 \\
\hline Others & 199 & 1.0 & 3.4 & 3.0 \\
\hline & 5597 & 495 & 92.1 & 842 \\
\hline High Frequency & 1049 & 50.5 & 7.9 & 15.8 \\
\hline \multicolumn{5}{|l|}{ Women's decision making } \\
\hline $\begin{array}{l}\text { Husbands/Others } \\
\text { Tus, }\end{array}$ & 2012 & 16.0 & 33.6 & 30.3 \\
\hline $\begin{array}{l}\text { Self/With husband's } \\
\text { Wealth index }\end{array}$ & & 84.0 & 66.4 & \\
\hline Poorest & 1972 & 4.2 & 35.5 & 29.7 \\
\hline Poorer & 1149 & .9 & 21.1 & 17.3 \\
\hline Middle & 1096 & 1.2 & 20.0 & 16.5 \\
\hline
\end{tabular}

is observed that $55.2 \%$ of women didn't receive ANC. This section presents the rural-urban socio-economic Notable variations in ANC utilization between women and demographic differentials in the utilization of in urban and rural areas were observed. Accordingly, skilled delivery. Table 2 presented the distribution of $81.5 \%$ of women from urban areas received ANC women according to skilled delivery care service utilicompared to $36.4 \%$ of women in rural areas (Table 1). zation by different predisposing and enabling factors. Of the total 6,641 births, only $15.6 \%$ were assisted by

Results of Bivariate Analysis: Levels of Skilled De- SBAs, while the remaining $84.4 \%$ delivered withou livery Care Service Utilization any assistance by SBAs. With regard to the association of the predictors with service utilization, the

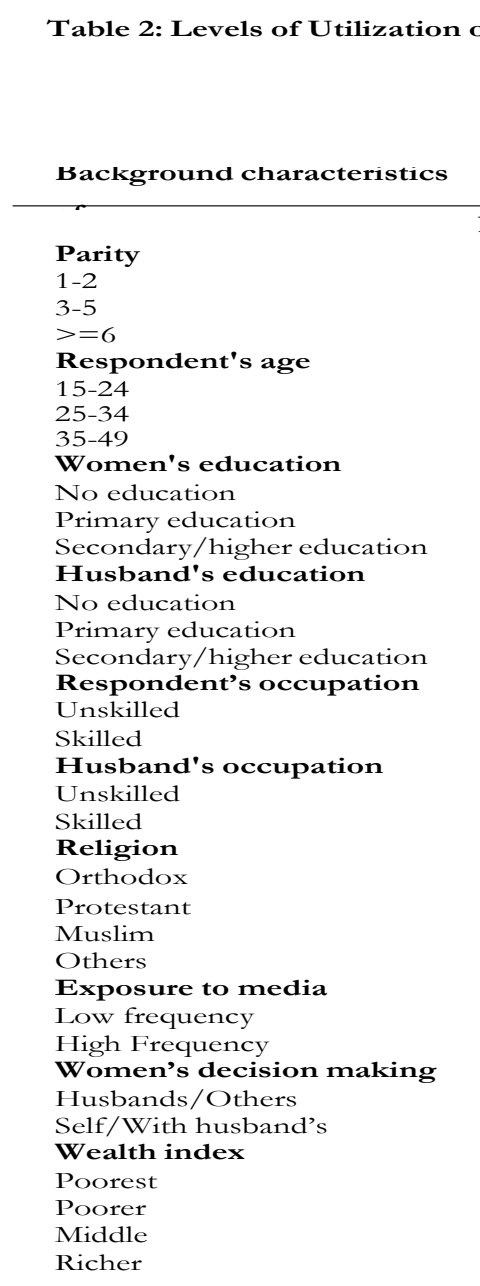

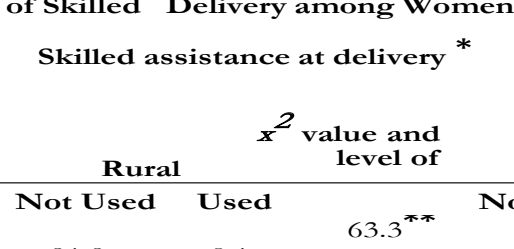

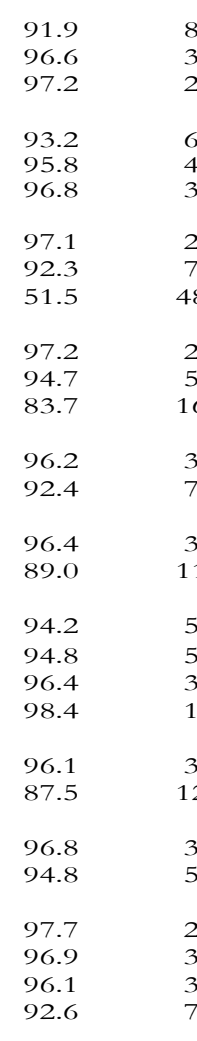

Chi-square association test showed that all the predictors considered in the study were significantly associated with utilization of skilled delivery in both rural and urban samples.

Skilled assistant includes doctor, nurse, and midwife.

Results of Bayesian logistic regression analysis

In this study, two separate models for urban and rural samples were fitted to see the determinants of utilizaion of skilled 15-49 who had at least one birth, five years preceding the 2011 EDHS. The first model (Rural Model) was fitted to identify the determinants of utilization of skilled

\begin{tabular}{ccc} 
& Urban & $\begin{array}{c}x^{2} \text { value and } \\
\text { level }\end{array}$ \\
\hline Not Used & Used & $181.2^{* *}$ \\
20.5 & 79.5 & \\
49.6 & 55.4 & \\
70.7 & 29.3 & \\
30.2 & 69.8 & $13.5^{*}$ \\
35.3 & 66.7 & \\
45.6 & 54.4 & $193.7^{* *}$ \\
60.5 & 39.5 & \\
31.3 & 68.7 & \\
12.4 & 87.6 & \\
66.5 & 33.5 & $149.2^{* *}$ \\
37.1 & 66.9 & \\
20.1 & 79.9 & \\
38.6 & 61.4 & $5.9^{*}$ \\
31.9 & 68.1 & $*$ \\
63.8 & 36.2 & $86.2^{*}$ \\
30.1 & 69.9 & \\
24.3 & 75.7 & $63.2^{*}$ \\
44.5 & 55.5 & \\
46.5 & 53.5 & \\
41.7 & 58.3 & \\
52.0 & 48.0 & $138.6^{* *}$ \\
19.9 & 80.1 & \\
52.5 & 47.5 & $28.6^{*}$ \\
32.6 & 67.4 & \\
76.9 & 23.1 & $140.0^{* *}$ \\
72.7 & 27.3 & \\
93.3 & 6.7 & \\
78 & &
\end{tabular}

delivery for rural women. The Second model (Urban Model) demonstrates the key predictors of utilization of Skilled delivery among women living in urban Ethio-

As indicated in Table 3, in rural women's sample, age of the women was not statistically significant while it significantly contributed to utilization of skilled delivery among women residing in urban Ethiopia. Accordingly, urban women in age group of 25-34 years and 35-49 have $45 \%$ and $107 \%$ higher odds of receiving

assistance from SBAs than women in the age group of $15-24$, respectively (table 3 ). 
With regard to parity of women, a significant nega-

Women in rural and urban areas who attended secondery. Among women residing in urban areas of Ethiopia ary or higher education are 5.22 and 2.28 times more with 3-5 and six or more births $63 \%$ and $82 \%$ of them likely, respectively, to receive assistance from SBAs durare less likely to deliver with the assistance of SBAs, ing delivery compared to those with no education (table respectively, than those who have one or more births,. 3).

Likewise, among women in the rural sample those with In the case of rural women, the influence of partner's birth order of six and above are $54 \%$ less likely to de- education on utilization of skilled delivery was not staliver with assistance of SBAs than those with one or tistically significant. Conversely, Table 3 showed that two births (Table 3).

women from urban areas whose husband's attended

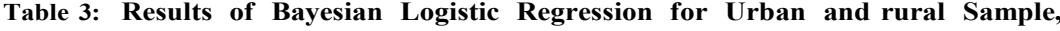

Ethiopia

\begin{tabular}{|c|c|c|}
\hline & $\begin{array}{l}\text { OR } \\
\text { (95\% Confidence } \\
\text { Intervals) } \\
\text { (Ruralodel) }\end{array}$ & 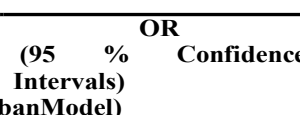 \\
\hline \multicolumn{3}{|l|}{ Age of women } \\
\hline $\begin{array}{l}15-24^{1} \\
25-34\end{array}$ & $\begin{array}{l}1.45^{*}(0.908,2.13)\end{array}$ & $\begin{array}{l}1.00 \\
1.12(0.77,1.63)\end{array}$ \\
\hline \multirow{2}{*}{\multicolumn{3}{|c|}{$2.07(1.19,3.64)$}} \\
\hline & & \\
\hline $\begin{array}{l}3-5 \\
>=6\end{array}$ & $0.37^{*}(0.25,0.54)$ & $0.51^{*}(0.35,0.74)$ \\
\hline \multicolumn{3}{|l|}{$\begin{array}{l}>=6 \\
\text { Women's educational status }\end{array}$} \\
\hline $\begin{array}{l}\text { No education } \\
\text { Primary education } \\
\text { Secondart/hicher }\end{array}$ & $1.48^{*}(1.00,2.10)$ & $\begin{array}{l}1.51^{*} 1.00 \\
5.09,2.10) \\
52 *^{*}(1.0610 .1034)\end{array}$ \\
\hline \multicolumn{3}{|l|}{ tional status } \\
\hline $\begin{array}{l}\text { No educatic } \\
\text { Primary }\end{array}$ & $\begin{array}{c}1.00 \\
1.54(1.03,3.12)\end{array}$ & $\begin{array}{c}1.00 \\
1.06(0.76,1.48)\end{array}$ \\
\hline \multicolumn{3}{|c|}{$1.94(1.21,3.30)$} \\
\hline $\begin{array}{l}\text { Unskilled } \\
\text { Skilled } \\
\text { Husband }\end{array}$ & $\begin{array}{c}1.00 \\
1.08(0.80,1.46)\end{array}$ & $\begin{array}{c}1.00 \\
1.21(0.88,1.65)\end{array}$ \\
\hline $\begin{array}{l}\text { Uusban } \\
\text { Unskille } \\
\text { Skilled }\end{array}$ & $2.21^{1.00}(1.49,3.30)$ & $\begin{array}{c}1.00 \\
1.35(0.93,1.93)\end{array}$ \\
\hline $\begin{array}{l}\text { Religi } \\
\text { Orthod }\end{array}$ & & \\
\hline & $84(0)-y$ & \\
\hline \multirow{2}{*}{\multicolumn{2}{|c|}{$\begin{array}{l}\text { Others } \\
\text { Wom sexposure to media } \\
\text { Less frequently }{ }^{1}\end{array}$}} & \\
\hline & & \\
\hline $\begin{array}{l}\text { iently } \\
\text { decision making }\end{array}$ & & \\
\hline & & \\
\hline
\end{tabular}

secondary or higher education have 1.94 times higher odds of using assistance from SBAs compared to wom- Urban women who have higher exposure to mass meen with uneducated husband. However, urban women dia were 1.56 times more likely to receive assistance whose husband's attended primary school didn't have a from SBAs during delivery against women with less exstatistically significant variation in receiving assistance posure to media; whereas exposure to media was not from SBAs compared to women whose husband's statistically influential predictor variable among women attended no education. Unlike the results of Bivariate in rural areas. Likewise, women's autonomy was not staanalysis, the influence of women's occupation on utili- tistically associated with utilization of skilled deliver zation of assistance from SBAs during delivery was not among women both in urban and rural areas. Women statistically significant in both urban and rural women. from others (Catholic /traditional/other) religion were Likewise, among women in rural sample, husband's oc- $73 \%$ less likely to receive assistance from SBAs comcupation didn't show statistically significant association pared to women from the Orthodox religion (Table 3). with use of skilled delivery care services.
The odds of receiving assistance from SBAs among women living in rural areas and belonging to richer and the richest wealth group were 2.01 and 3.09 times higher, respectively compared to those from poorest wealth quintile. Similarly, women from urban areas who belong to richer and the richest wealth group were 1.17 and 3.38 times higher, respectively compared to women from poorest wealth quintile. The likelihood of receiving skilled assistance during delivery is 3.06 and 4.16 times higher for women who attended ANC,in urban and rural areas, respectively, than women who did not attend ANC, (Table 3).

\section{Discusion}

This study examined the urban-rural differentials in the status and predictors of utilization of SBAs based on a total of 6,644 sample women. It was observed that about $15.6 \%$ of the women attended skilled assistance during delivery. The level of use of maternal health services noted here is one of the lowest compared to Sub-Saharan African countries, such as Cameroon (62\%), Senegal (62\%), Malawi (57\%), and Lesotho (52 $\%$ ), (Macro International, 2007).

Results of the analysis of Bayesian logistic regression showed that different socio- economic and demographic variables were associated strongly with women's use of skilled delivery care services in both urban and rural areas.

One of the predisposing demographic factors considered in this study was women's age. Although its association with utilization of skilled delivery in the rural sample was not statistically significant, it was observed that there was positive relationship between age and use of SBAs in urban sample. Contrary to women's age, birth order was found to have a strong negative association with the use of SBAs during delivery in both urban and rural women. With regard to predisposing factors; parental education, husband's and women's education emerged as weak predictors of the use of skilled assistance at delivery among urban and rural women. Likewise, it was observed that women's exposure to media and women's autonomy to be statistically not significant factors to influence rural women's tendency towards utilizing skilled delivery.

Previous studies documented that women's education is a major factor influencing maternal health service utilization ${ }^{7,11,18,24}$. Education serves as proxy for information and knowledge of available health care services ducation also serves as proxy for women's higher socio-economic status that improves the ability of educated women to afford the cost of health care services ?. Moreover, education enhances level of autonomy of women and increases their decision-making power that results in improved freedom to make decisions including the use of maternal health care services ${ }^{2,7}$. Furthermore, educated women are considered to have bette knowledge and information on modern health care services ${ }^{5}$. A Tanzanian study reported that educated women were more likely to make decision to use assistance from medical personnel at delivery compared to their uneducated counterparts ${ }^{21}$. Women's education was found to be a strong determinant of the use of skilled assistance at delivery in Bangladesh' ${ }^{9}$ and in Turkey?

The study revealed that husband's education is statistically not significant predictor of the utilization of SBAs during delivery among rural women. In the case of urban women sample, statistically significant difference was observed only for those women whose husband's attained secondary or higher education. This finding conforms to some other previous studies in Ethiopia and other countries ${ }^{27,25}$. It is likely that educated partners will have a better understanding and knowledge of modern health care services. Education also leads to better awareness about available services ${ }^{27}$.

A significant negative association was seen between higher birth order and the use of SBAs at delivery in both urban and rural sample. These findings concur with several other studies that came up with negative association between higher birth order and the use of skilled delivery assistance ${ }^{27,18}$. This association can be explained by fear of complication or lack of confidence among women who experience first birth and thus, are more likely to use SBAs at delivery than among those with higher birth order ${ }^{18}$. Conversely, women with more children believe that they are more experienced to give birth safely and hence, are less likely to use skilled assistance during delivery (Mekonnen et al 2003). The low use of SBAs during delivery among women with high number of children could also be due to resource constraints in the family as there are many demands in the family (Mekonnen et al 2003).

Women's occupation was found to be statistically not significant predictor in influencing utilization of assistance from SBAs in both rural and urban sample. Nevertheless, women in urban sample whose husbands worked in skilled work such as business and services 
were found to be more likely to use SBAs during delivery compared to the women whose husbands involved in unskilled work. This finding is consistent with study conducted in Ethiopia and Bangladesh indicating husband's occupation as a significant predictor to use skilled assistance at delivery (Tsegay et al, 2013 and Chakraborty et al, 2002). Husband's occupation also serves as proxy for household economic status. As a result, as the household economic status increases, the women's tendency towards using skilled assistance at delivery also increases.

In this study, religion emerged as a weak predictor of utilization of skilled assistance. The finding was consistent with study conducted by Mehari, 2013, who analyzed the EDHS 2000 and 2005 and come with weak association of women's religion and utilization of skilled delivery care services. Contrary to this finding, other studies in Ethiopia and other countries found significant association between religion and skilled delivery service utilization (Addai, 1998 \& Mekonnen and Mekonnen, 2002). Thus, as to how religion influences skilled delivery service utilization needs further studies to ascertain.

The likelihood of skilled delivery service utilization among women in the poorer and middle wealth quintile compared to women in the poorest wealth quintile was not statistically significant among both urban and rural women.

Exposure to media was influential factor of delivery service utilization among women in urban areas. This finding concurs with another study in Ethiopia which analyzed EDHS 2000 and 2005 (Mehari, 2013). Contrary to the findings of a study conducted by (Mulumebet et al, 2011), this study depicted the disparities in receiving assistance from SBAs during delivery that stems from low levels of decision making power to be not statistically significant in both samples.

Finally, lower rate of ANC and skilled delivery service utilization has been reputable contributing factors for higher rate of maternal mortality. This study revealed that ANC utilization is a strong predictor of utilization of skilled assistance during delivery. This is also consistent with findings of studies in other countries

Letamo et al, 2003). However, only $9 \%$ women who the ssistance during delivery. This low figure could partially be explained by the unpredictability of onset of labour together with poor infrastructure like roads fo tansportation which make access difficult (Babalola et 1, 2009).

\section{Conclusion and policy implications}

Despite the efforts that have been made in recent year to improve maternal health outcomes in Ethiopia, the proportion of women who receive assistance from SBAs is still unacceptably low. This study has identified a number of important factors that influence the use of skilled assistance during delivery. These predictors vary in urban and rural areas despite the fact that some of them have appeared important variables in both samples.

The strong relationship between education and the outcome variable implies that informal adult education fo women and men can be employed as an immediate in tervention to provide basic education and to increase awareness about basic maternity care. In line with this, raising awareness about the use of SBAs among women and men through mass media, religious leaders and community elders should be given due attention. The study has also concluded that large proportion of rural women do not use SBAs even after receiving ANC services, implying that there is a need to enhance the quality and follow up with a major focus on providing appropriate advice on safe delivery, i.e. proper scaling up of ANC service will more likely be followed with delivery assistance services once access is not a constraint.

\section{References}

Aboubakary Sanou, Seraphin Simboro, Bocar Kouyaté, Marylène Dugas, Janice Graham, and Gilles Bibeau (2010). Assessment of factors associated with complete immunization coverage in children aged 12 23 months: a cross-sectional study in Nouna district, Burkina Faso

2. Acharya, D.R., Bell, J.S., Simkhada, P., Van Teijlingen, E.R., Regmi, P.R. (2010). Women's autonomy in household decision-making: a demographic study in Nepal. Reproductive health, doi: 10.1186/1742-4755-7-15.

3. Addai, I. (1998). Demographic and socio-cultural factors influencing use of maternal health services in
Ghana. African Journal of Reproductive Health, 2(1), 73-80. 4. Anderson, R. (1995). Revisiting the Behavioral Model and Access to Medical Care: Does it Matter? Journal of Health and Social Behavior, 36(1), 1-10.

5. Babalola, S. Fatusi, A. (2009). Determinants of us of maternal health services in Nigeria-- looking beyond individual and household factors. BMC Pregnancy Childbirth. 9(1), 35.Belay, T. (1997). Correlates of antenatal care attendance among women in Yirgalem town and surrounding peasant associations, Southern Ethiopia; 1997 (unpublished M.Sc. thesis).

6. Campbell, O.M. \& Graham W.J. (2006). Strategies for reducing maternal mortality: getting on with what works, Lancet series, 368(9543), 1284-99.

7. Celik, Y. and Hotchkiss, D.R. (2000). The socio-econom determinants of maternal bealth care utilization in Turkey. Soc Sci. Med., 50(12),1797-806.

8. Central Statistical Agency (CSA), Addis Ababa, Ethiopia and ORC Macro.Ethiopia, Demographic and Health Survey 2011, Final report. (2012). Calverton, Maryland, USA. Central Statistical Agency of Ethiopia (2008). Population Census Commission E.Summary and statistical report of the 2007 population and housing census. Addis Ababa, Ethiopia.

9. Chakraborty, N., Islam, M.A., Chowdhury, R.I. Wasimul Bari, W., \& Akhter H.H. (2003). Determinants of the use of maternal health services in rural Bangladesh. Health Promotion International, 18 (4), 327-337. 10. Chakraborty, N., Islam, MA., Chowdhury, R.I. \& Bari, W. (2002). Utilisation of postnatal care in Bangladesh: evidence from a longitudinal study. Health and Social Care in the Community, 10(6), 492-502. 11.Dagne E.(2010) Role of socio-demographic factors on utilization of maternal health care services in Ethiopia, MSc. Thesis, Umeå University.

12. Federal Democratic Republic of Ethiopia Ministr of Health (2006). National reproductive health strategy, 2006-2015.

13. Federal Ministry of Health (2005) Planning and Programming Department, Health Sector Strategic Plan (HSDP-III) 2005/6-2009/10.Geneva, Switzerland.

14. Griffiths, P., \& Stephenson, R. (2001). Understanding users' perspectives of barriers to materna health care use in Maharashtra, India. Journal of Biosocial Science.

5. Letamo, G., Rakgoasi, S.D.(2003). Factors associated with non-use of maternal health services in Botswana. Journal of Health Population Nutrition, 21(1), 40-7. 16. Mehari, A. (2013). Levels and Determinants of Use of Institutional Delivery Care Services among Women
Childbearing Age in Ethiopia: Analysis of EDHS 2000 and 2005 Data. ICF International Calverton, Maryland, USA.

17. Mekonnen, Y. and Mekonen, A. (2002). Utilization of Maternal Health Care Services in Ethiopia. Calverton, Maryland, USA: ORC Macro.

18. Mekonnen Y., \& Mekonnen A. (2003). Factors influencing the use of maternal healthcare services in Ethiopia. Journal of Health Population and Nutrition, 21, 374-382 19. Mengistu, M., and J. James (1996). Determinants of antenatal care utilization in Arsi Zone, Central Ethiopia. Ethiopia Journal of Health Development. (3):171-178.

20. Mihret, H., Mesganaw, F. (2008). Birth preparedness and complication readiness among women in Adigrat town, northern Ethiopia. EthiopJHealth Dev, 22(1), 14 20.

21. Mrisho, M., Schellenberg, J.A., Mushi,A.K, Obrist,B., Mshinda, H., Tanner,M., Schellenberg ,D.(2007). Factors affecting home delivery in rural Tanzania, Tropical Medicine \& International Health Volume 12, Issue 7 pages 862-872.

22. Mulumebet, A., Abebe, G., Tefera, B.(2002). Predictors of safe delivery service utilization in Arsi zone, South-east Ethiopia. Ethiop J Health Sci. Vol. 21, Special Issue, 111-112.

23. Nigatu R. (2011). Antenatal and Postnatal Care Service Utilization in Southern Ethiopia: A Population-Based Study. African Health Sciences Vol 11 No 3 September 2011

4. Nigussie, M., Haile Mariam, D., Mitike, G. (2004). Assessment of safe delivery service utilization among women of childbearing age in north Gondar Zone. Ethiopian Journal of Health Development, 18(3), 14-152.

25. Paul, B.K. \& Rumsey, D.J. (2002). Utilization of rural Bangladesh: an empirical study. Social Science and Medicine, 54, 1755- 1765

26. Shaikh, T., \& Hatcher, J. (2005). Health seeking behavior and health services utilization in Pakistan: Challenging the policy makers. Journal of public bealth, 27(1), $49-54$

27. Thind, A., Mohani, A., Banerjee, K., Hagigi, F. (2008). Where to deliver? Analysis of choice of delivery location from a national survey in India. Bio Med Central Public Health, (29), doi:10.1186/1471-2458-8-29.

28. Tsegay, Y., Gebrehiwot, T., Goicolea,I., Edin, K., Lemma, H., and San Sebastian, M. (2013). Determinants of antenatal and delivery care utilization in Tigray region, Ethiopia: a cross- sectional study. International Journal for Equity in Health, 12(30).

29. United Nations (2012), The millennium development goals report 2012 
30. New York: NY WHO (2005). The World Health Report: Make every mother and child count. World Health Organization, Geneva. Switzerland.

31. WHO (2008). Proportion of births attended by a skilled attendant - 2008 updates. Department of Reproductive Health and Research, Geneva. Switzerland. 32.WHO (2010). Trends in maternal mortality: 1990 to 2008: Estimates developed by WHO, UNICEF, UNFPA and The World Bank. 2010; Geneva: World
Health Organization.

33. WHO, Maternal mortality ratio (per 100000 live births), 2010; Available from:http://who.int/ healthinfo/statistics/indmaternalmortality/en/index. html.(Accessed: February 3, 2013).

34. World Bank, Ethiopia (2013), International Development Association, Press release, Available from: http://go.worldbank.org/9ZGSQ69LZ0 (Accessed: May 28, 2013). 